\title{
Dietary supplementation of 3-hydroxy-3-methylbutyrate improves catch-up growth in underfed lambs
}

\author{
P Ostaszewski ${ }^{1}$, I Papet ${ }^{1}$, S Nissen 2, F Glomot ${ }^{1}$, J Grizard ${ }^{1}$, M Arnal ${ }^{1}$ \\ 1 INRA, Laboratoire d'Étude du Métabolisme Azoté, \\ Theix, 63122 Saint-Genès-Champanelle, France; \\ 2 lowa State University, Ames, IA, USA
}

Leucine is transaminated to $\alpha$-ketoisocaprioate then partially metabolized in 3-hydroxy-3-methylbutyrate (HMB). Leucine and its metabolites are potential stimulators of growth rate (May and Buse, 1989). The purpose of this study was to assess the effect of dietary supplementaticn of HMB on catch-up growth in underfed lambs.

Twelve male lambs (lle-de-France $\times$ Romanov) weighing about $22 \mathrm{~kg}$ were individually housed in crates in a temperature and humidity contrilled environment. They were fed once a day a ground concentrate (17\% protein) and a hay. After 1.5 week adjustment period, half of the animals rizceived a dietary supplement of $\mathrm{Ca}-\mathrm{HMB}(0.1 \% \mathrm{DM}$ of the concentrate for 2 weeks followed by $0.35 \%$ for 7 weeks). Since HMB is stable in the rumen its salt was directly mixed with the concentrate. The control group was fed a diet with $\mathrm{CaCO}_{3}$ (the same supply of $\mathrm{Ca}$ as in the $\mathrm{Ca}-\mathrm{HMB}$ diet). During the 9 weeks of experiment the level of feeding was as follows: 2 weeks of feeding semiad libitum (concentrate $3 \%$ of live body weight, hay ad libitum), $9 \mathrm{~d}$ of strong food restriction (concentration $2.2 \%$, hay $0.6 \%$ ), 5.5 weeks of moderate restriction (concentrate $2.8 \%$, hay $0.7 \%)$.

The growth rate of lambs fed semi-ad libitum was not modified by the $0.1 \%$ supplementation of $\mathrm{HMB}$ (table I). After the strong food restriction, the increase in food intake led to a period of catchup growth in both groups, lasting about 1 week. This rise in growth rate was $102 \%$ higher in the group of animals fed the diet supplemented with HMB $(0.35 \%)$ than in the control group (table I). Despite the lack of any further effect of HMB, the overall body weight gain was $26 \%$ higher in the group of animals receiving HMB than in the control animals.

Our data indicate that the HMB supplementation enhanced the catch-up growth rate in underfed lambs. This is of interest in animal production.

May and Buse (1989) Diabetes, Metab Rev 5, 227-245

Table I. Growth response to different dietary regime supplemented with $\mathrm{Ca}-\mathrm{HMB}$.

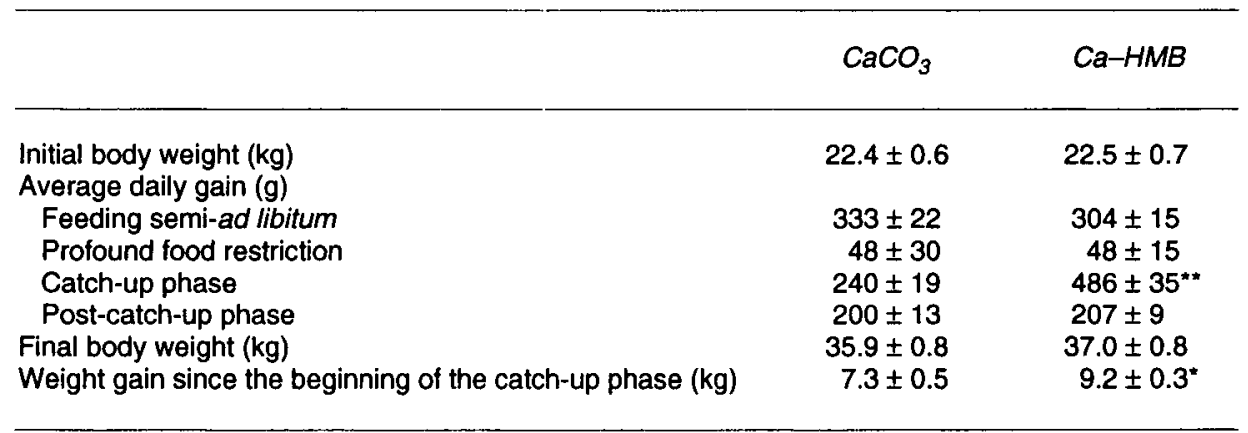

$* P<0.01 ; * * P<0.001$ 